\title{
Reviewer's comment concerning "Surgical treatment of thoracic disc herniations via tailored posterior approaches" (doi:10.1007/s00586-011-1821-7 R1 by W. Börm et al.)
}

\author{
G. Guizzardi
}

Received: 10 May 2011/Published online: 19 May 2011

(C) Springer-Verlag 2011

This paper reports the idea of the authors on the possibility to find "a posterior-tailored approach" for the surgical treatment of thoracic disc herniations. This possibility is based essentially on the site of pathology; approaches related to localization at different levels of the thoracic spine. The results of the study in terms of local pain reduction, of radicular pain, increased motor strength, sensitivity and myelopathy improvement and JOA score are almost similar to those reported in other series with a higher number of patients [1]. First of all, I congratulate the authors for the effort made to systematize this pathology because only a few centers in the world have great experience and relevant series. I am also really convinced that they made every effort to introduce the reviewers' tips in their paper, and everyone agrees to cancel the open thoracotomy approaches in this pathology, especially, for the high rate of morbidity. However, we must not forget that today, the surgical approaches to thoracic disc herniations may not only include costo-transversectomy, lateral extracavitary, foraminotomy, transfacet and/or transpedicular, and interlaminar. Today it is mandatory to include and hold onto endoscopic approaches, or at least transpendicular approaches with endoscopic assistance, as key choices for median and or calcified disc herniations [2]. On the other hand, we are completely convinced that the learning curve for this technique is really long, especially given to the low number of cases that the majority of spine departments receive each year. Exactly for this reason, unless in an emergency due to rapid neurological deteriorations, these patients should be treated and sent to the most appropriate reference centers. Finally, I believe that the most important criteria in the decision of a surgical strategy should be a contemporary balance between clinical data, type of hernia, soft or hard, but in particular the place of the same with respect to the spinal canal: median, paramedian, lateral or far lateral. So their results are commendable, but the correlation between these parameters was not considered [3].

\section{References}

1. Anand N, Regan JJ (2002) Video-assisted thoracoscopic surgery for thoracic disc disease: Classification and outcome study of 100 consecutive cases with a 2 -year minimum follow-up period. Spine 27(8):871-879

2. Burke TG, Caputy AJ (2000) Treatment of thoracic disc herniation: evolution toward the minimally invasive thoracoscopic technique. Neurosur Focus 9(4):E9, 1-7

3. Cervellini P (2006) Treatment of thoracic disc herniation. AO Spine Comprehensive Course, Rome, November 6/8
G. Guizzardi ( $\square)$

Spine Section, Neurosurgical Department, University and City Hospital Careggi, Florence, Italy

e-mail: euydgu@tin.it 